\title{
Magnetotelluric investigations for the seismically active area in Northern Miyagi Prefecture, northeastern Japan
}

\author{
Masahiro Ichiki ${ }^{1,4}$, Masaaki Mishina ${ }^{2}$, Tadanori Goto ${ }^{3}$, Naoto Oshiman ${ }^{1}$, Norihiko Sumitomo ${ }^{1}$, and Hisashi Utada ${ }^{4}$ \\ ${ }^{1}$ Research Center for Earthquake Prediction, Disaster Prevention Research Institute, Kyoto University, Gokasho, Uji, Kyoto 611-0011, Japan \\ ${ }^{2}$ Research Center for Prediction of Earthquakes and Volcanic Eruptions, Graduate School of Science, \\ Tohoku University, Aoba, Aramaki, Aoba-ku, Sendai, Miyagi 980-8578, Japan \\ ${ }^{3}$ Department of Environmental Earth Science, Faculty of Education, Aichi University of Education, \\ 1 Hirosawa, Igatani, Kariya, Aichi 448-8542, Japan \\ ${ }^{4}$ Ocean Hemisphere Research Center, Earthquake Research Institute, University of Tokyo, 1-1-1 Yayoi, Bunkyo-ku, Tokyo 113-0032, Japan
}

(Received July 27, 1998; Revised May 28, 1999; Accepted June 9, 1999)

\begin{abstract}
The ELF- and the ULF-MT surveys were carried out in the northern part of Miyagi Prefecture, northeastern Japan. This area is one of the most seismically active areas in this region, where hypocenters of microearthquakes are distributed on a fault plane at depths from 2 to $16 \mathrm{~km}$. The aim of the present study is to investigate the relationship between electrical resistivity structure and the hypocentral distribution of microearthquakes in the area. The calculated impedance tensor at each site has been obtained from the observed data and decomposed to remove galvanic distortion, provided that the regional strike is $\mathrm{N} 32^{\circ} \mathrm{E}$ to obtain the 2-D apparent resistivity and phase responses. The resistivity structure obtained by the inversion process using smoothness constraint shows that the relatively electrically conductive layer at depths from 4 to $10 \mathrm{~km}$ corresponds to the zone where the microearthquakes occur. The fact that the conductive zone correlates with the hypocentral zone is probably attributed to fluids in the crust. Another more conductive block is found at depths from 1 to $3.5 \mathrm{~km}$ and the bottom boundary of this conductor appears to restrict the uppermost depth where the microearthquakes occur. This subsurface conductor is interpreted as a marine sediment deposited during the Tertiary period. In the lower crust, the relatively conductive blocks (lower than $5 \Omega \cdot \mathrm{m}$ ) exist below a depth of $15 \mathrm{~km}$.
\end{abstract}

\section{Introduction}

It has been considered that occurrence of earthquakes in the earth's crust is not only due to stress concentration but also due to decrease in effective confining pressure with pore pressure increasing in the source region. Such increase of pore pressure is expected to be induced by penetration of pressurized fluids in the crust (Nur, 1972; Scholz et al., 1973). From a viewpoint of electrical resistivity (reciprocal of the electrical conductivity), both stress concentration and fluid penetration reduce the bulk resistivity in the upper or middle crust. If stress concentration raises pore pressure and pore connectivity, the bulk resistivity is expected to decrease (e.g. Bahr, 1997). On the other hand, fluid penetration also reduces the bulk resistivity, since the bulk resistivity of rocks depends largely on water content (e.g. Olhoeft, 1981). Hence it is natural to hypothesize that source region is electrically conductive and a good correlation exists between distribution of hypocenters and resistivity structure in the crust.

In the northern part of Miyagi Prefecture, located in northeastern Japan, a cluster of microearthquakes has been found at depths shallower than $16 \mathrm{~km}$. The cluster of microearthquakes is located around the hypocenter of the 1962 Northern Miyagi Earthquake (M 6.5). Kono et al. (1993)

Copy right $(\mathrm{C}$ The Society of Geomagnetism and Earth, Planetary and Space Sciences (SGEPSS); The Seismological Society of Japan; The Volcanological Society of Japan; The Geodetic Society of Japan; The Japanese Society for Planetary Sciences. recently investigated the seismicity around this hypocentral zone in detail by setting up a temporary seismic network and pointed out two features; (1) the present microearthquakes are interpreted as aftershocks of the 1962 Earthquake since the daily frequency of microearthquakes obeys the modified Omori formula (e.g. Utsu, 1957), and (2) most of hypocenters are found on a plane which strikes $\mathrm{N} 30^{\circ} \mathrm{E}$ and dips $50^{\circ} \mathrm{NW}$ which corresponds to one of the nodal planes of the focal mechanism solution of the 1962 main shock. This fault plane geometry implies a two-dimensional (2-D) resistivity distribution in this area, if we believe above hypothesis.

In 1993, the Research Group for Crustal Resistivity Structure in Japan (referred to as RGCRS hereafter) carried out a cooperative experiment of the TDEM (Time Domain Electromagnetic Method), the ELF (Extremely Low Frequency)and the ULF (Ultra Low Frequency)—MT (magnetotelluric) in the northern part of Miyagi Prefecture which is one of the most seismically active areas in northeastern Japan.

In this paper, we, representative of the RGCRS, analyzed the ELF- and ULF-MT data and examined the correspondence of conductive zone with hypocentral zone in this area. The resistivity distribution was constructed by the 2-D inversion and the MT impedance tensors were decomposed into several matrices to remove galvanic effects. The TDEM data were already analyzed and inverted to one-dimensional (1-D) resistivity model (Kanda et al., 1996), which will be 


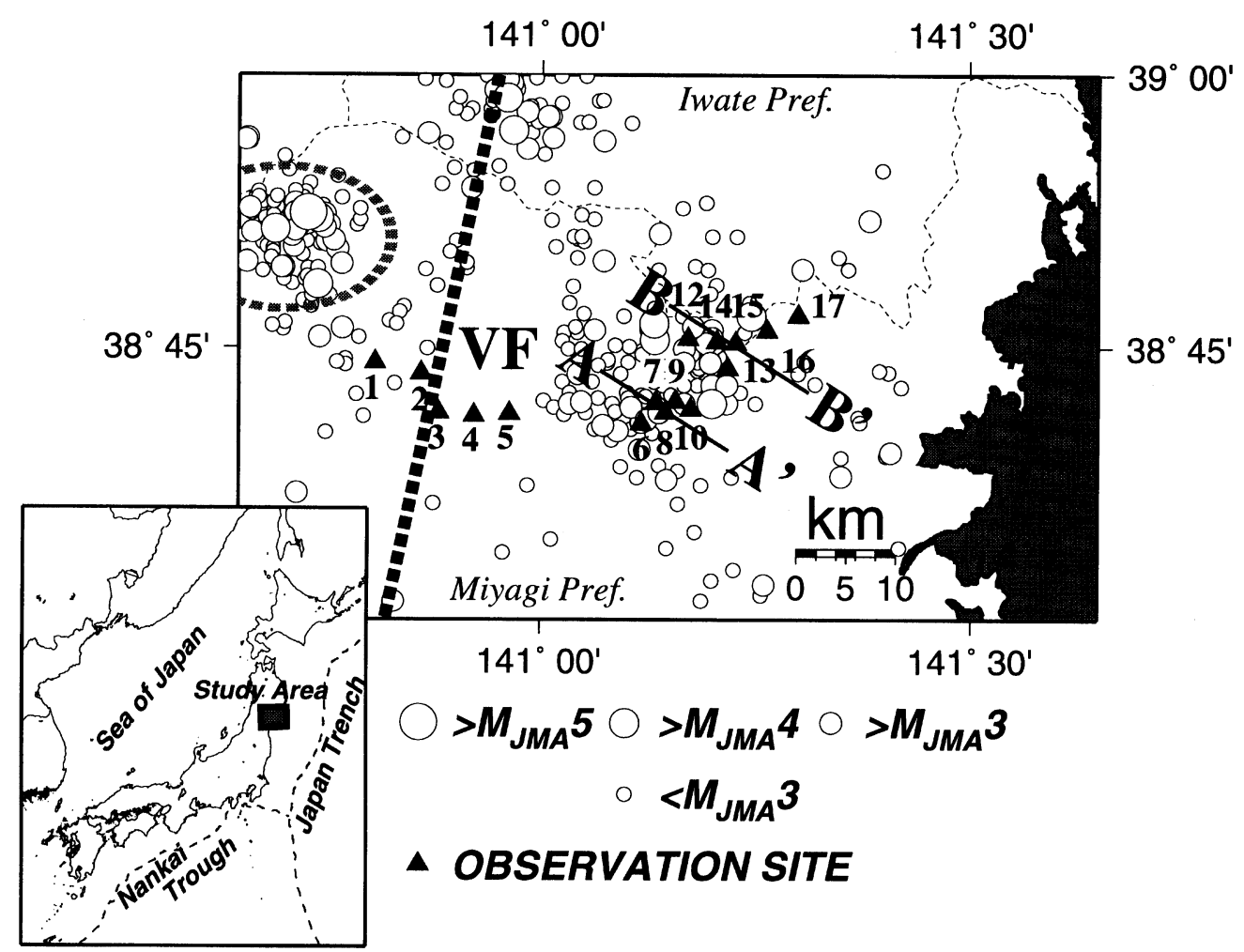

Fig. 1. Site locations for the ELF- and the ULF-MT surveys (triangles). Open circles show the epicenters of microearthquakes occurring at depths shallower than $30 \mathrm{~km}$ from 1980 to 1995 . They were determined by JMA (Japan Meteorological Agency) seismic network. Thick dotted line indicates the volcanic front (VF). A-A' and B-B' are the profile lines analyzed herein. A gray broken line surrounds the Kurikoma geothermal area.

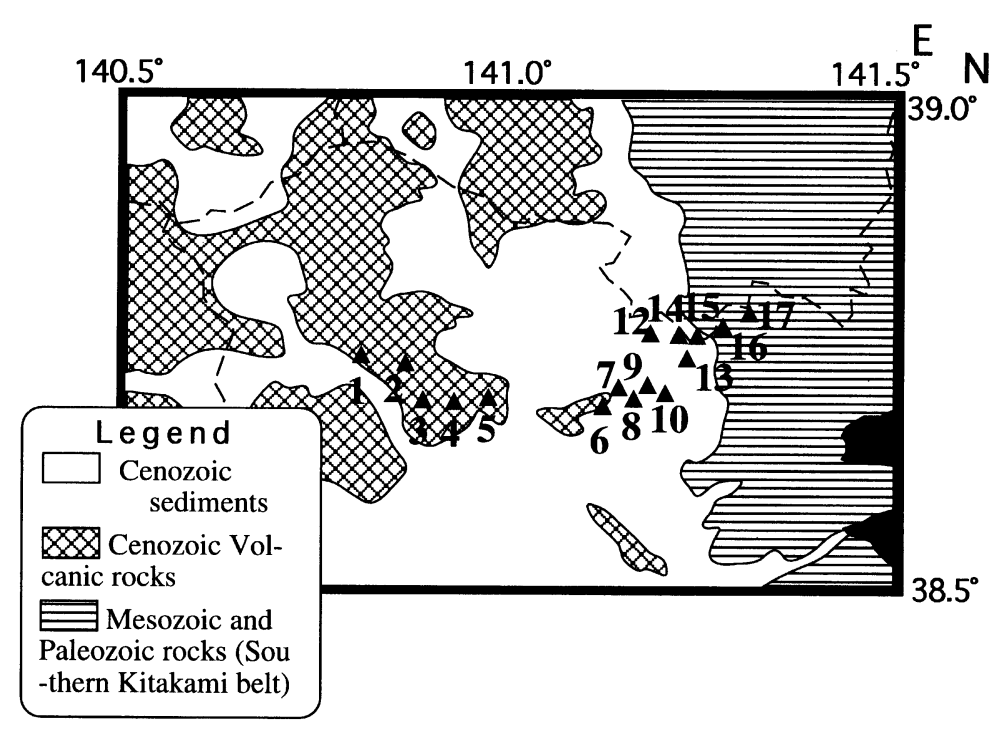

Fig. 2. Surface geological domains around the study area. Southern Kitakami belt consists of sedimentary rocks (sandstone, mudstone and conglomerate) and metasediments (limestone, chert and slate). Cenozoic volcanic area contains rhyolite, dacite, andesite in Neogene and Quaternary. Cenozoic sediment domain is composed of volcanic ash, tuff, sandstone, mudstone, conglomerate, sand and mud in Neogene and Quaternary.

compared with our MT result in the later section.

\section{ELF- and ULF-MT Data Acquisition}

The ELF-MT and ULF-MT surveys were carried out at 17 sites respectively across the epicentral zone from west to east as illustrated in Fig. 1. We used Tierra Tecnica's U30 and U36 systems for the ULF-MT which cover the period band from 10 to 1000 seconds. The 10 sites equipped with U36 (Sites 6 to 15 in Fig. 1) are located in the epicentral zone. The site distribution is originally designed for the TDEM 
observation. The TDEM experiment was carried out during the daytime and the MT signals were recorded during night time. At other sites equipped with U30, only MT signals were obtained. There is a large gap in site distribution between Sites 5 and 6 where highway and Shinkansen lines run from north to south.

We observed three components of the magnetic field and two components of the electric fields with $1 \mathrm{pT}$ and $1 \mu \mathrm{V}$ system resolution in the ULF-MT, respectively. The sampling rate was $1 \mathrm{~Hz}$ at each site. Clocks of U30 and U36 systems have relative accuracy of $10^{-8}$ and synchronized with each other. This clock accuracy enabled the remote-reference pro-

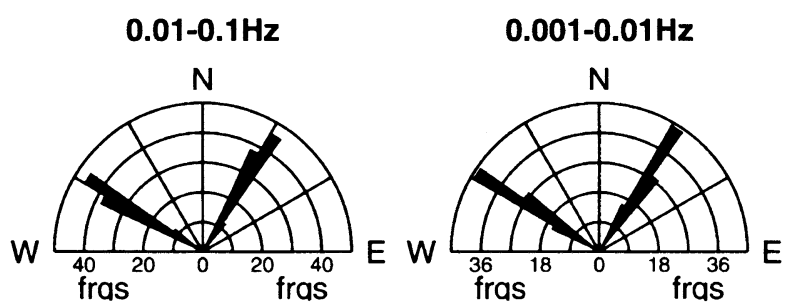

Fig. 3. Rose diagrams of the principal axes accumulated for all sites. The diagrams for the two frequency bands are represented separately. Since principal axes have uncertainty in $90^{\circ}$, the diagrams are symmetrical at every $90^{\circ}$. cessing to remove bias errors (Gamble et al., 1979). There is a DC-powered railway in the study area and the ULF-MT measurements were carried out only during night time when the railway is not operated. At most of the sites, the ULFMT data were acquired over successive 4 nights. However we could obtain no data of sufficient quality at Site 11 owing to an instrumental trouble, which is excluded in Fig. 1, and the length of the data at Sites 2 and 3 were not enough to realize a analysis. We did not construct the 2 -D model along Sites 1 to 5, because the effective analyses can not be carried out by only three sites (Sites 1, 4 and 5). Then we tried to construct two 2-D resistivity models using the data of Sites 1 to 10 and Sites 6 to 10 . However, there is no difference between the two resistivity distributions of the hypocentral zone. Therefore we will describe the analyses using the data of epicentral sites (Sites 6 to 17).

The ELF-MT data were collected using Tierra Tecnica's EL529 system. Vertical component of the magnetic field was not acquired in the ELF-MT survey. The frequency band of 8 to $20 \mathrm{~Hz}$ (Schumann resonance) was particularly concerned with in the ELF-MT survey. Impedance tensor elements are calculated by the built-in software within the system from time series data for about 30 minutes at each site.

Figure 2 illustrates a simplified geologic map around the observation sites (after Yamada et al., 1982; Oide et al., 1989). The study area is located in the NE-Japan fore arc. Surface geology of study area can be classified into three

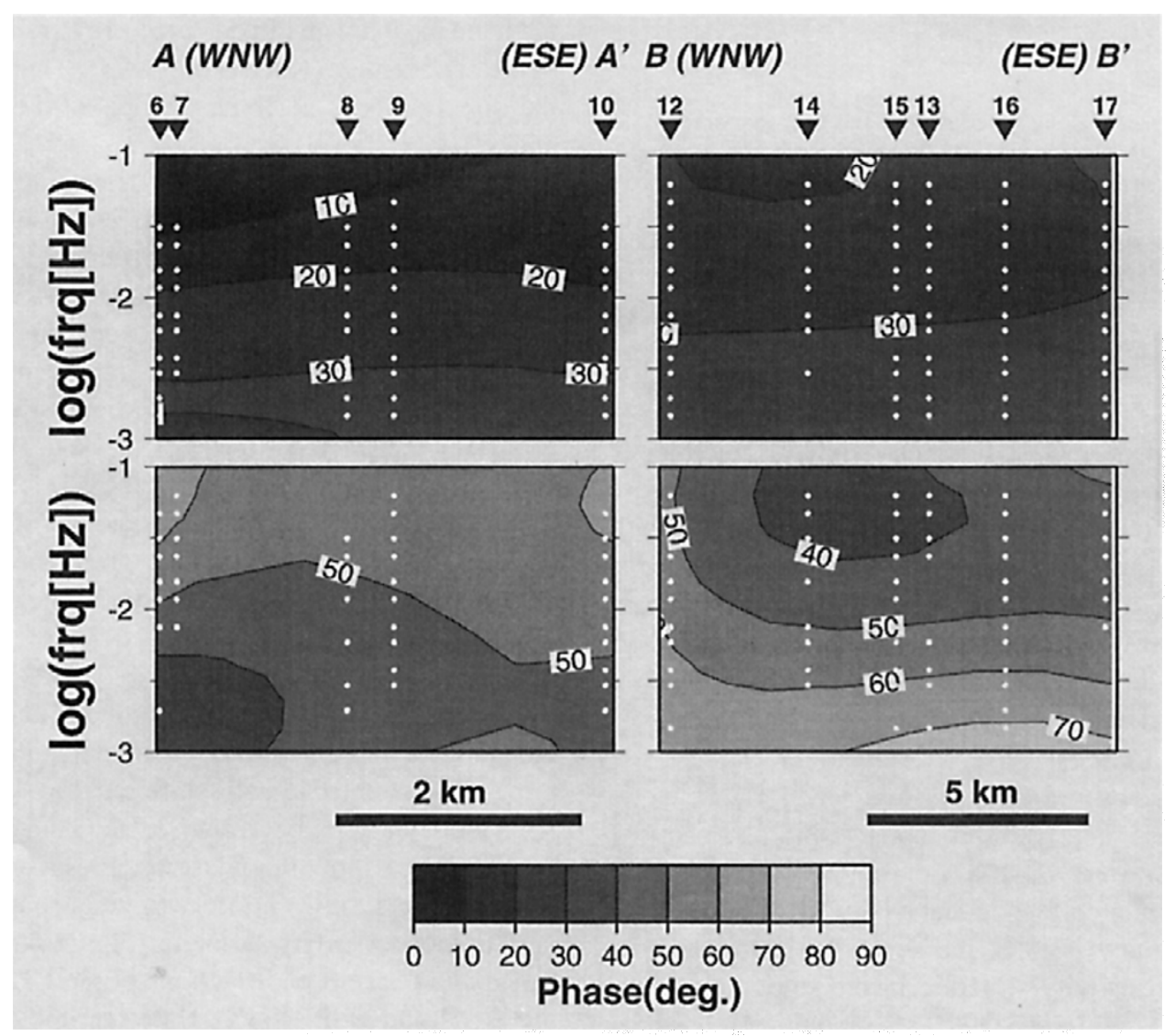

Fig. 4. TM (upper) and TE (lower) mode phase pseudosections along the A-A'(left) and B-B'(right) lines illustrated in Fig. 1. The low TM mode phase responses at high frequency along the $A-A^{\prime}$ profile indicate that the near surface conductor is embedded adjacent Site 6 and the TE mode high phase responses at low frequency along the B-B' profile represent the existence of a deep conductive block. 


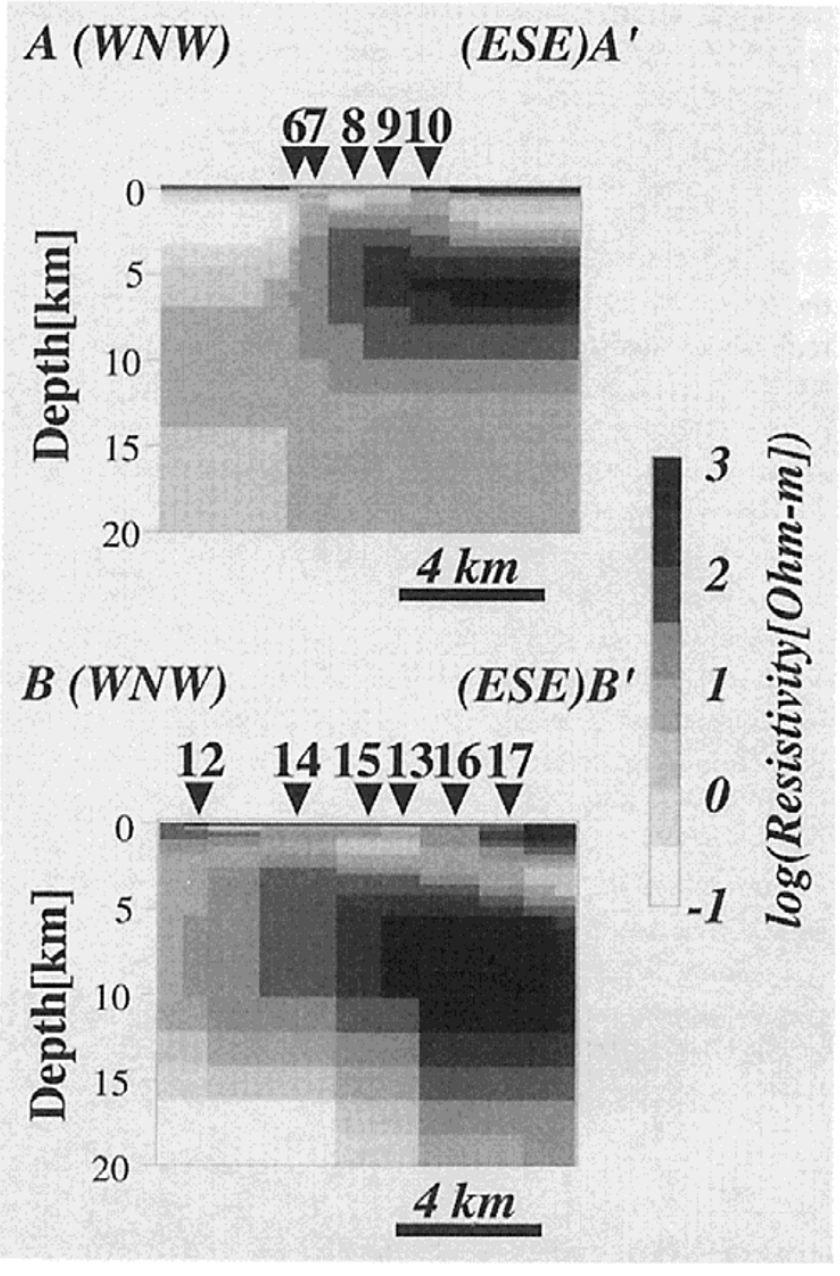

Fig. 5. Resistivity model along the A-A'(top) and B-B'(bottom) profiles obtained by 2-D ABIC inversion. The inverted responses are the TM mode apparent resistivity responses and both of the TE and TM modes phase responses. The resistive blocks in the east-south-eastern part at depths from about 4 to $10 \mathrm{~km}$ is found along both of the profiles. Along the A-A' profile, the near surface conductor is seen near Site 6. Along the B-B' profile, a conductor at the lower crust is detected at depths deeper than $15 \mathrm{~km}$.

blocks, sedimentary, metasedimentary and volcanic blocks, as shown in the legend. The basement is exposed in the eastern part of this area near Sites 16 and 17. Most of the study area is covered with sedimentary rocks of the Miocene to Holocene age. These widespread sedimentary rocks make the subsurface structure highly conductive, as will be described in more details in the later sections.

\section{MT Data Processing}

\subsection{Strike determination}

The time series data were processed using a robust processing code (Chave et al., 1987) to remove outliers.

If we assume the correspondence between a hypocentral zone and a conductive zone, the seismological studies indicate that the resistivity structure in the study area is approximately 2-D. With respect to 2-D modeling, it has been recently recognized that the electrical strike can be sometimes misled owing to local 3-D heterogeneity by the conventional 2-D treatment (Bahr, 1988; Jones and Groom, 1993). Groom and Bailey (1989) developed a MT impedance tensor decomposition technique by which one can discriminate the influence of local 3-D heterogeneity from the regional 2-D responses. Chave and Smith (1994) and Smith (1997) have further improved the technique. In this study, the GroomBailey (G-B) decomposition have been carried out. The influences of local 3-D heterogeneity are characterized by four distortion parameters in the G-B decomposition technique. Two of those parameters - twist and shear-cause deflection of the regional strike. However, the G-B decomposition technique enables us to estimate the two parameters from observed impedance tensors.

In using the G-B decomposition, we should note the operational order of determination of the distortion parameters and the principal axes, one of which coincides with the regional strike. Jones and Groom (1993) emphasize that shear and twist parameters are more robust than regional strike. Following this result, we tried to decompose the observed impedance tensors in three steps; (1) decomposition without any constraint, (2) estimation of shear and twist at each site and (3) determination of the regional strike direction with twist and shear constrained. Directions of the principal axes estimated in such a way are shown in Fig. 3. Figure 3 is illustrated in the two representative periods and at intervals of five degrees. It is noted that the directions are almost independent of frequency (period) and that the direction of the principal axes are almost same for all sites.

The average directions of the principal axes for all sites and frequencies are $\mathrm{N} 32^{\circ} \mathrm{E}$ and $\mathrm{N} 58^{\circ} \mathrm{W}$. Furthermore, $\mathrm{N} 32^{\circ} \mathrm{E}$ almost coincides with the tectonic strike inferred from both the focal mechanism (Takagi et al., 1973) and the distribution of the hypocenters (Kono et al., 1993). Therefore we adopted the direction $\mathrm{N} 32^{\circ} \mathrm{E}$ as the regional strike direction in this area.

Since the regional strike was determined to be $\mathrm{N} 32^{\circ} \mathrm{E}$ as described above, we divided MT responses into the TE and TM modes. However it turned out impossible to explain responses for all sites by a unique 2-D resistivity model. Because the response curves between the neighboring sites along one profile are sometimes significantly different. The TE and TM mode responses can be characterized into two groups by the site locations; (1) Sites 6 to 10 and (2) Sites 12 to 17 . This more or less suggests the 3-D tendency. However 3-D modeling is not practical yet and therefore we separately constructed a 2-D model for each group, on the A-A' and BB' profiles (see Fig. 1) comprising of Sites 6 to 10 and Sites 12 to 17 , respectively.

\subsection{Phase pseudosections}

The G-B decomposition technique is unable to determine the site gain and anisotropy parameters uniquely. These parameters are related to static shift (e.g. Jones, 1988), which affects more the apparent resistivity than the impedance phase. Therefore we show the phase pseudosections along the $\mathrm{A}-$ $\mathrm{A}^{\prime}$ and $\mathrm{B}-\mathrm{B}$ ' profiles in order to get a rough idea about the variation of resistivity structure. Figure 4 shows the TE and TM mode phase pseudosections of the ULF-MT data along the $\mathrm{A}-\mathrm{A}^{\prime}$ and $\mathrm{B}-\mathrm{B}^{\prime}$ lines. Note that the ordinate is a logfrequency scale which is a non-linear function of depth and that the distance scales of pseudosections along the A-A' and B-B' are different from each other.

The TM mode phase pseudosection indicates that the lat- 

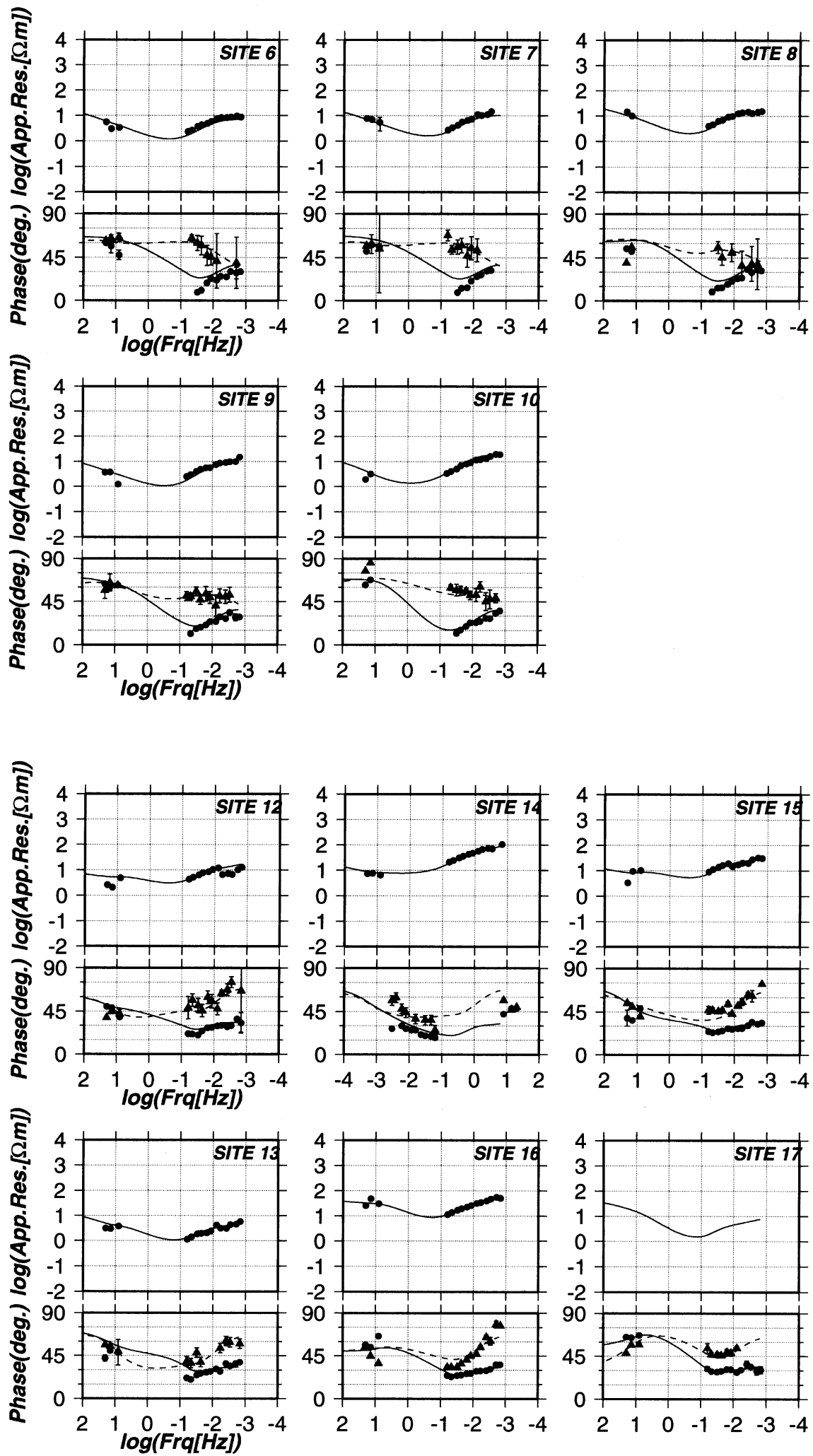

Fig. 6. Fit of sounding curves derived from the model. Solid circles: observed responses of TM mode. Solid triangles: observed TE mode phase responses Solid lines: calculated TM mode sounding curves. Broken lines: calculated TE mode sounding curves. Some observed responses are reduced owing to missing the trends evidently. Since the apparent resistivity responses observed at Site 17 were not smooth, they were not used in the inversion. 


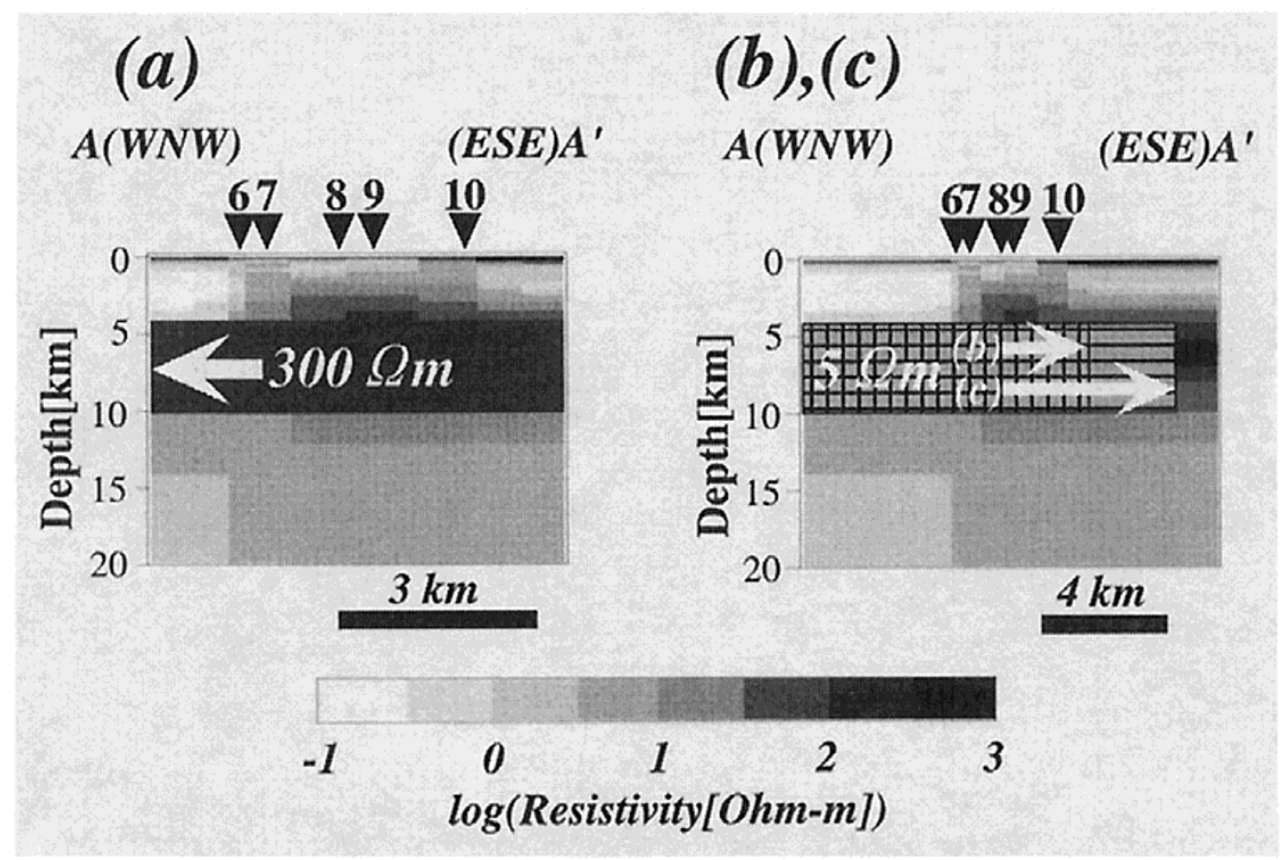

Fig. 7. The models modified to check the resolution of the resistive block along the A-A' profile. Each model is modified as (a) extending the resistive block toward WNW, (b) shortening the resistive block to Site 10 and (c) shortening the resistive block to 4 km away from Site 10 , respectively.

eral variations are small in both the A-A' and B-B' profiles. However, the TM mode phase responses at high frequencies are lower near Sites 6, 7 along the A-A' profile and Sites 14, 15 along the B-B' profile. These indicate that more conductive zones exist in the near surface.

Although the trends of the TM mode pseudosections are similar feature between the A-A' and B-B' profiles, the TE mode pseudosections are obviously different. Along the $\mathrm{B}-$ B' profile, the TE mode phase responses rise as frequency decreases and are as high as 70 degrees at lowest frequencies. This feature is not recognized in the TE mode pseudosection along the A-A' profile. This feature indicates that the deeper structure along the $\mathrm{B}-\mathrm{B}^{\prime}$ profile is more conductive than the A-A' profile.

\section{The 2-D Inversion}

The apparent resistivity and phase responses along the A$\mathrm{A}^{\prime}$ and $\mathrm{B}-\mathrm{B}$ ' profiles have been inverted to 2-D resistivity models. As described in the previous section, both TE and TM mode apparent resistivity responses are possibly affected by static shift in a 3-D/2-D (locally 3-D superimposed on regional 2-D) structure. However, as far as the TM mode apparent resistivity is concerned, static shift can be involved in the 2-D modeling scheme (Goto, 1997; Goto et al., 1997). Hence we carried out the 2-D inversion using the TM mode apparent resistivity responses and the both TE and TM mode phase responses. A superficial (the thickness is $100 \mathrm{~m}$ ) block beneath each site was constrained to the apparent resistivity responses obtained by the VLF (Very Low Frequency)-MT results at $22.3 \mathrm{kHz}$.

2-D inversion was carried out by a code with ABIC (Akaike Bayesian Information Criterion) smoothness constraint (Uchida, 1993; Uchida and Ogawa, 1993). MT responses for each profile were inverted separately using the ABIC inversion method. Small weights are adopted to

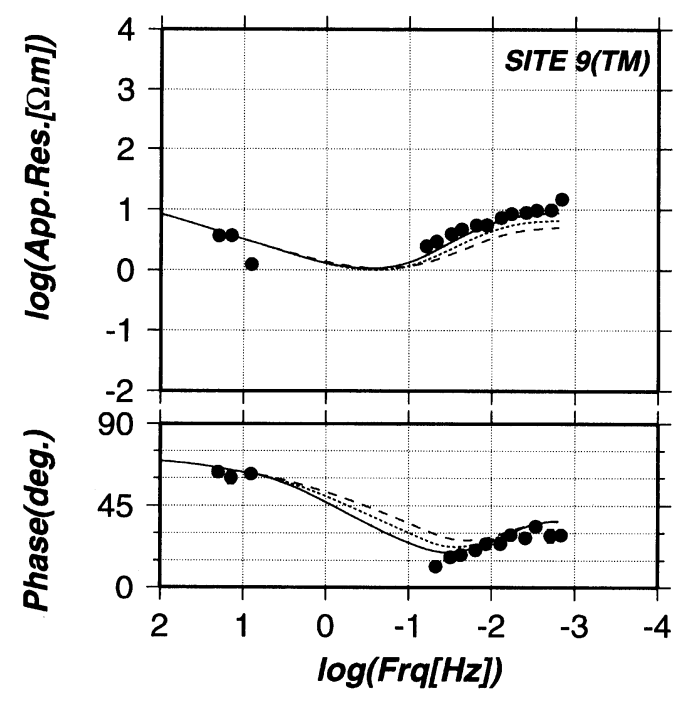

Fig. 8. The TM mode sounding curves obtained from the models illustrated in Figs. 7(a), (b) and (c). Solid circles show the observed responses. The error bars are so small that they are buried in the solid circles. Solid line represents the sounding curve derived from the model in Fig. 6. Dotted line is calculated from model (b). Broken line is calculated from model (c). Essentially the same curve is derived from model (a).

smoothness for shallow blocks to effectively correct the static shift as shown by Goto (1997).

The 2-D resistivity models obtained by the inversion for the $\mathrm{A}-\mathrm{A}^{\prime}$ and $\mathrm{B}-\mathrm{B}$ ' profiles are shown in Fig. 5. Response curves observed and calculated at each site are illustrated in Fig. 6. The fit is generally good with root mean square error less than $5 \%$.

The following three features can be derived from the resistivity models. (1) At depths from about 5 to $12 \mathrm{~km}$, a 


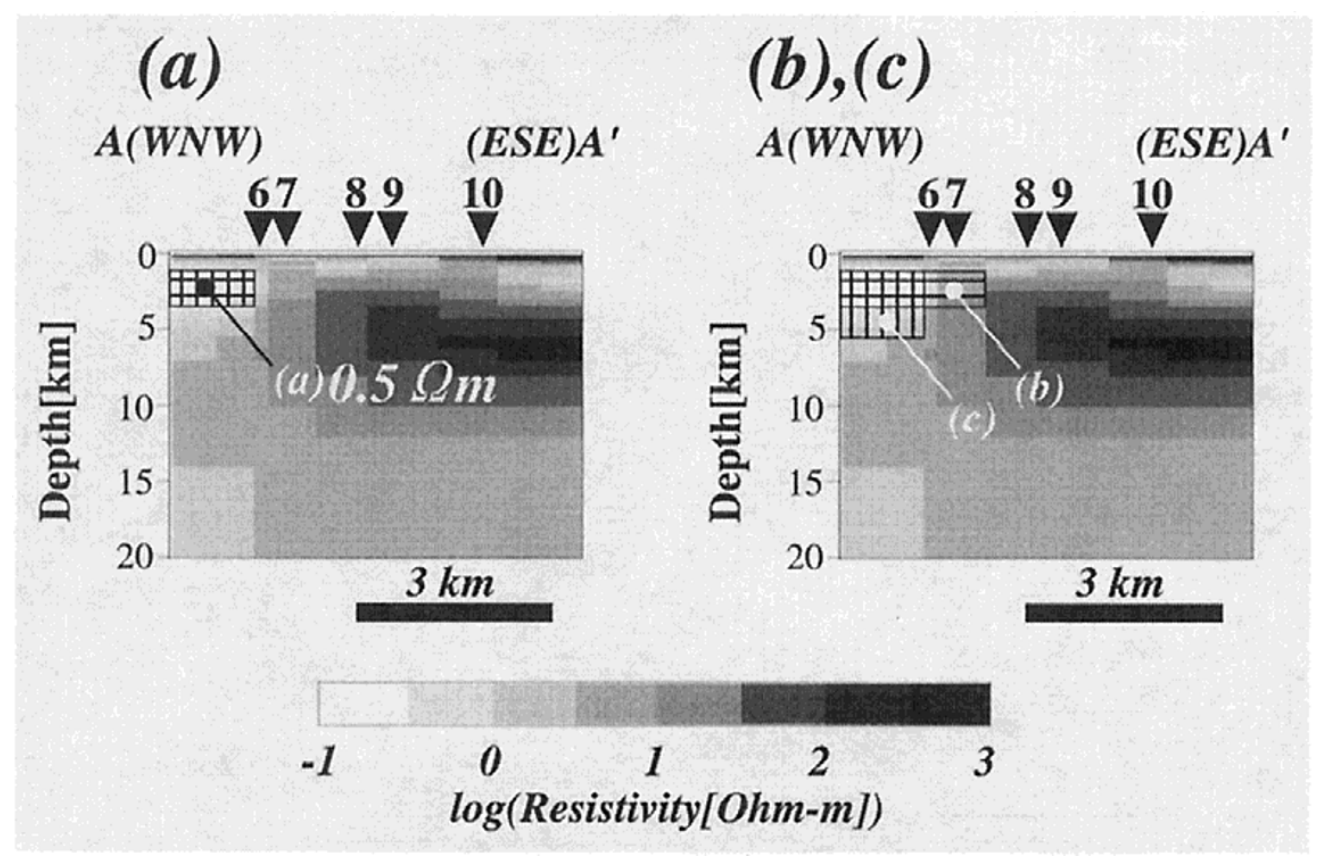

Fig. 9. The modified models to check the resolution of the near surface conductor in the A-A' profile. In model (a), the resistivity of the conductor is changed to $0.5 \Omega \cdot \mathrm{m}$. In model (b), the conductive area is extended laterally to Site 7 with the constant resistivity of the original model. The model (c) is constructed by the same way as the model (b) except extending vertically to $6 \mathrm{~km}$ in depth.

comparatively resistive block exists towards right hand side (ESE) of both profiles. The resistivity of the block beneath the A-A' profile is about $200 \sim 400 \Omega \cdot \mathrm{m}$, while that beneath the $\mathrm{B}-\mathrm{B}^{\prime}$ profile is $1000 \sim 2000 \Omega \cdot \mathrm{m}$. (2) In left hand side of $A-A^{\prime}$ profile, a near surface conductor (below $0.3 \Omega \cdot \mathrm{m}$ ) exists at depths from 1 to $3.5 \mathrm{~km}$ but is absent along the B-B' profile. This extremely low resistivity is comparable to that of sea water. (3) As indicated by the TE mode phase pseudosection along the B-B' profile (Fig. 4), another conductor can be recognized in the deeper part. We refer this conductor as "the lower crust conductor" hereafter. The resistivity at the corresponding zone beneath the $\mathrm{A}-\mathrm{A}$ ' profile is also lower than those of the surrounding blocks (Fig. 5). However the presence of conductor beneath the A-A' profile is not so evident.

\section{Sensitivity Test}

In this section, we try to confirm the resolution of the present model characterized by the three features described in the previous section. The sensitivity tests are carried out by 2-D forward modeling (Rodi, 1976), in which we change resistivity value and size of each particular block.

\subsection{The resistive blocks}

To confirm whether the conductive zone surely corresponds to the hypocentral zone, it is necessary to examine the resolution of the resistive block in both the A-A' and B-B' profiles, described as the feature (1) in the previous section.

We first examined the influence of extending the resistive block towards WNW at depths from 4 to $10 \mathrm{~km}$ along the AA' profile. The resistivity value was kept as $300 \Omega \cdot \mathrm{m}$ which was about the average resistivity inside the block (case (a) in Fig. 7). In spite of extending the resistive zone over 50 $\mathrm{km}$ away from Site 6 , the response curves did not change. On the other hand, when the resistive zone was shortened, the fit between the calculated and observed responses became evidently worse. If the resistive block at depths from 4 to $10 \mathrm{~km}$ was gradually replaced by a conductive block ( 5 $\Omega \cdot \mathrm{m}$ ) in the left hand side of the A-A' profile (cases (b) and (c) in Fig. 7), the misfit to the observed responses became significantly large as shown in Fig. 8.

These results show that the resistive block is surely needed to account for the TM mode responses, although its lateral resolution is poor towards WNW direction. A similar tendency was also confirmed along the B-B' profile.

\subsection{Near surface conductor along $A-A^{\prime}$ profile}

A conductive block was supposed to exist near surface towards the left hand side of Site 6 along the A-A' profile (Fig. 5). This near-surface conductor is extremely conductive (about $0.3 \Omega \cdot \mathrm{m}$ ) and lies at depths from 1 to $3.5 \mathrm{~km}$. In order to examine the resolution of this conductor, we tested three models in which parameters describing the conductor were changed as follows; (a) the resistivity was increased to 0.5 $\Omega \cdot \mathrm{m}$ (Fig. 9), (b) the zone was extended laterally by $1 \mathrm{~km}$ toward ESE as shown by the horizontal stripes in Fig. 9, and (c) the zone was extended vertically to $6 \mathrm{~km}$ depth as denoted by the vertical stripes in Fig. 9 .

Figure 10 (a) shows the TE mode phase responses calculated from model (a) of Fig. 9 at Site 6 . The resistivity change produced a misfit beyond the standard errors of the TE mode phase responses at Sites 6 and 7. Figure 10(b) shows the TM mode apparent resistivity and phase responses obtained from model (b) of Fig. 9 at Site 6. The responses are significantly different from the observed ones. The response calculated from model (c) at Site 8 is shown in Fig. 10(c). The vertical extension changes the responses of Site 8 rather than Site 6 . As mentioned above, the conductor along the A-A' profile is well resolved. 
(a)

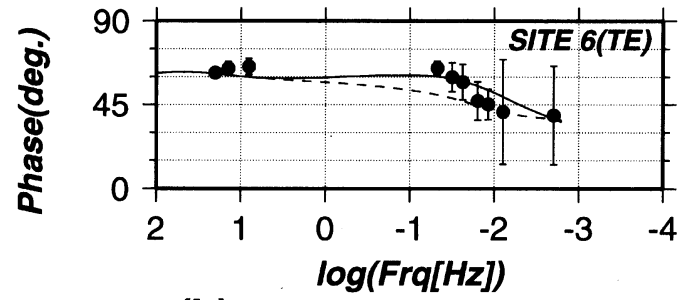

(b)

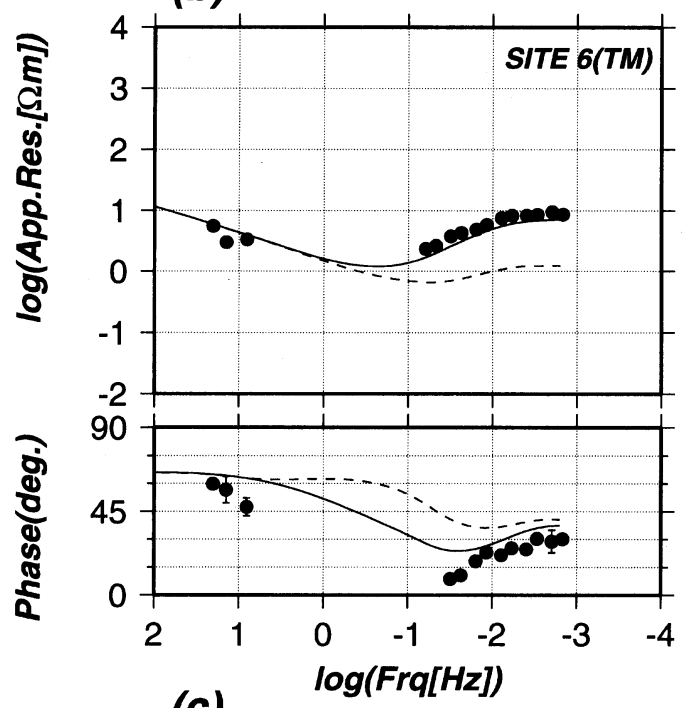

(c)

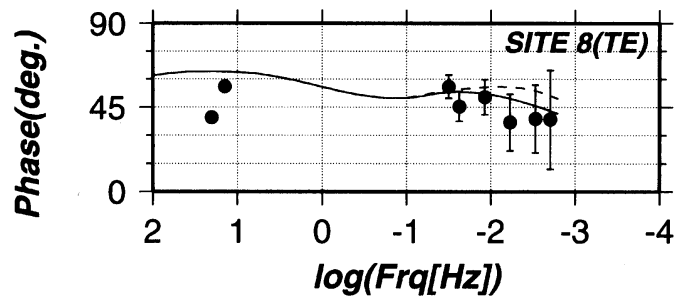

Fig. 10. The sounding curves obtained from the models illustrated in Figs. 9(a), (b) and (c). (a): The broken line indicates the TE mode sounding curve of phase response calculated from the modified model shown in Fig. 9(a). (b): The TM mode apparent resistivity and phase responses at Site 6 calculated from the modified model shown in Fig. 9(b) (broken line). (c): The broken line represents the TE mode sounding curve of the phase responses at Site 8 . The broken line significantly deviates from the observed responses. Each solid line in (a), (b) and (c) represents the sounding curve obtained from the original model.

\subsection{The lower crust conductor along the B-B' profile}

The resistivity structure deeper than $15 \mathrm{~km}$ depth along the $\mathrm{A}-\mathrm{A}^{\prime}$ profile is laterally uniform. The uniformity was tested by a forward modeling in which the resistivity of the part deeper than $14 \mathrm{~km}$ is constrained to $5 \Omega \cdot \mathrm{m}$ uniformly along the A-A' profile. The calculated response curve did not make significant difference for both modes.

On the other hand, the lower crust conductor along the B-B' profile is required for a satisfactory fit in the TE mode phase responses at lower frequencies. Presence of the conductor explains the increase of the TE mode phase responses at lower frequencies well. We increased the resistivity of the lower crust conductor along the B-B' profile from about 0.3 $\Omega \cdot \mathrm{m}$ to $1 \Omega \cdot \mathrm{m}$ and then to $5 \Omega \cdot \mathrm{m}$, in order to examine the reso-

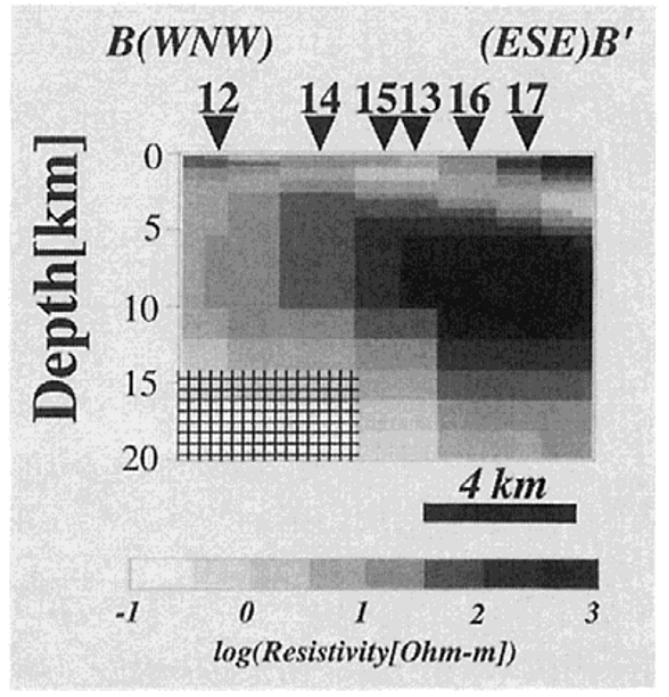

Fig. 11. The modified models to check the resolution of the lower crust conductor along the B-B' profile. The resistivity of the mesh part is changed to 1 and $5 \Omega \cdot \mathrm{m}$, respectively.

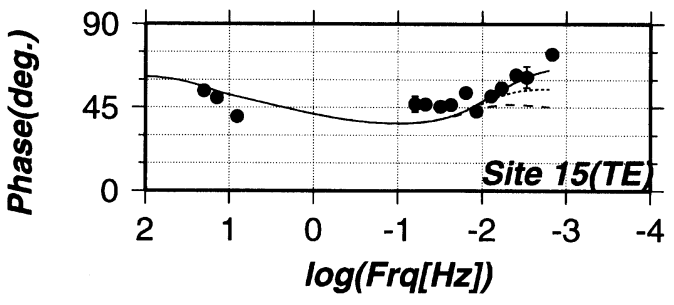

Fig. 12. The TE mode sounding curves calculated from the models illustrated in Fig. 11. The increasing of the resistivity of the lower crust conductor results in changing the calculated response curves as indicated by dotted line $(1 \Omega \cdot \mathrm{m})$ and broken line $(5 \Omega \cdot \mathrm{m})$, respectively.

lution of the resistivity of the lower crust conductor (Fig. 11). The dotted $(1 \Omega \cdot \mathrm{m})$ and broken lines $(5 \Omega \cdot \mathrm{m})$ in Fig. 12 are the TE mode phase response curves at Site 15 calculated for respective models. We can recognize that the resistivity of the lower crust conductor along the B-B' profile is lower than $1 \Omega \cdot \mathrm{m}$. Moreover, this sensitivity check revealed that the phase responses greater than $60^{\circ}$ at the lower frequency along the B-B' profile, is indeed caused by the lower crust conductor.

\section{Discussion}

We hypothesized the correspondence between conductive and hypocentral zones, then examined the hypothesis in the northern part of Miyagi Prefecture. Result can be summarized in Fig. 13 that we illustrate the hypocenters of recent microearthquakes (Kono and Mishina, Personal comm.) superposed on the resistivity structure in each profile.

The cluster of microearthquakes is likely to be bounded by the resistive block at depths from 4 to $10 \mathrm{~km}$ and the microearthquakes seem to occur in the relatively conductive zone. However, the resolution of the resistive block towards left hand side (WNW) is not good as described in the previous section. Shankland and Ander (1983), Harinarayana (1998) 


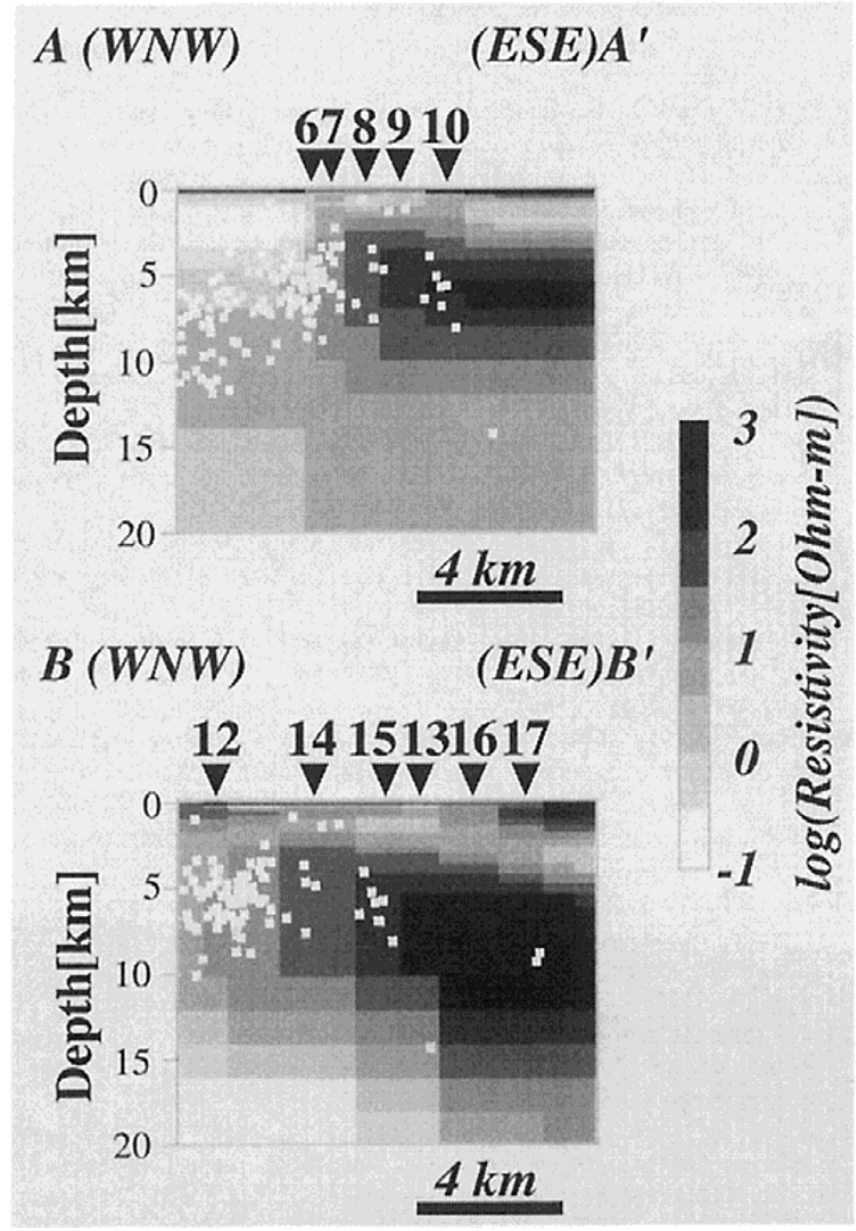

Fig. 13. Hypocenters of microearthquakes (Kono and Mishina, Personal comm.) superposed on the resistivity structure along the A-A' and B-B' profile. White squares represent the hypocenters, which were observed from Oct. 9, 1991 to Mar. 22, 1993

and others also pointed out that resistive blocks are not as well resolved as conductors in MT. Our result coincides with this feature. The poor resolution of the resistive block can be also attributed to the lack of sites between Sites 5 and 6 .

Causes of conductors in the crust has been discussed in many works (e.g. Kariya and Shankland, 1983; Hyndman, 1988; Jödicke, 1992). Three possible causes are (1) high temperature or presence of partial melts, (2) existence of the conductive minerals such as magnetite or graphite, and (3) existence of fluids (e.g. free water, constitution water, adsorptive water). As far as the relatively conductive zone is concerned where the microearthquakes occur, we emphasize that the fluids are most responsible. Because fluids can enhance both electrical conductivity and seismicity in the crust, if we assume the following situation. It has been considered that earthquakes in the crust are not only due to stress concentrations but also due to decrease in effective confining pressures owing to increasing pore pressures in the source region. The stress concentration increases the connectivity of pore fluids, which varies the exponent of porosity in Archie's law (Mogi et al., 1986; Bahr, 1997). The penetration of fluids into the source region increases the fluids content, which eventually decreases the bulk resistivity (e.g. Olhoeft, 1981).

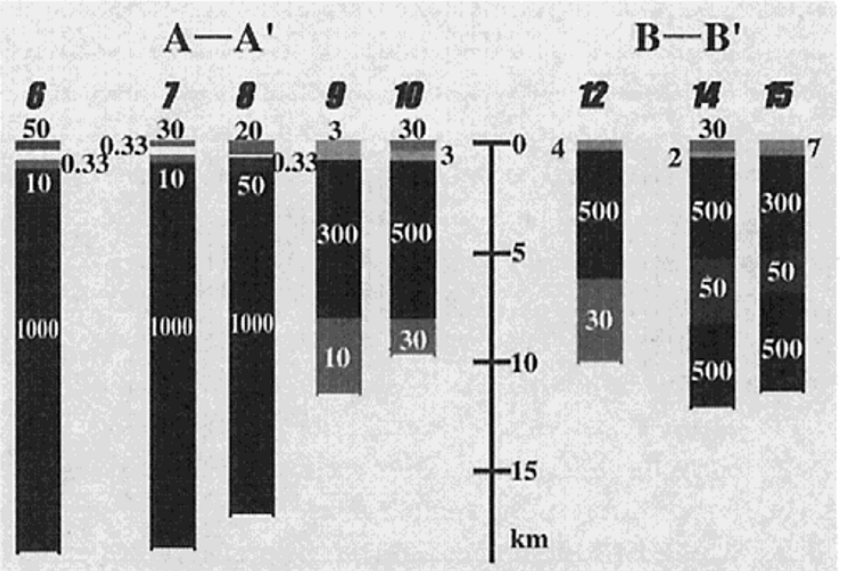

Fig. 14. The 1-D resistivity models at Sites 6 to 15 inferred from TDEM investigation (after figure 10 in Kanda et al. (1996)). The unit in $\Omega \cdot \mathrm{m}$.

Accordingly, fluid is a presumable candidate for the cause of the conductor in the hypocentral zone and similar observations support this hypothesis (Gupta et al., 1996; Zhao et al., 1996).

In respect of the origin of fluids, Kanda et al. (1996) speculated that fluids are provided by the migration of the free water dehydrated from the subducting Pacific slab. However, the origin of fluids in the crust cannot be generally identified uniquely as suggested by drilling and geochemical studies (e.g. Frape and Fritz, 1984; Möller et al., 1997). For example, ancient meteoric water and brine deposited in the study area are other promising candidates for the origin of the crustal conductor (Fujimoto, Personal comm.). Therefore chemical composition analyses of fluids (e.g. ${ }^{3} \mathrm{He} /{ }^{4} \mathrm{He}$ and so on) are required to discriminate the origin, which is beyond of the scope of this present paper.

The seismicity seems to disappear in the near surface and lower crust conductors. It is well known that inland seismicity is generally not active in the uppermost and lower crust. The near surface conductor can be inferred to be marine sediments, since its resistivity is approximately equal to that of sea water. Low seismicity at shallower part can be ascribed to the low rigidity of the sediments. On the other hand, the lower crust conductor has provoked a great deal of controversy since 1980's (e.g. Shankland and Ander, 1983; Hyndman, 1988). Ogawa (1992) reviewed seismic and electromagnetic studies of lower crust and summarized that the lower crust is mechanically ductile, seismologically reflective and electrically conductive. Hyndman (1988) proposed a model in which the cause of the lower crust conductor in the subduction zones is presence of free water originated from dehydration of subducting plate and depth of the conductor corresponds with $350 \sim 400{ }^{\circ} \mathrm{C}$ isotherm (e.g. Hyndman, 1988). Similar interpretation is likely to be applicable for the lower crust conductor revealed by the present study.

Lastly, we compared the resistivity model inferred from the present MT survey with that from TDEM results by Kanda et al. (1996) as shown in Fig. 14. The extremely conductive layer $(0.33 \Omega \cdot \mathrm{m})$ at shallower depth of $2 \mathrm{~km}$ below Sites 6 to 8 in the TDEM result seems to correspond to the near surface conductor along the $\mathrm{A}-\mathrm{A}^{\prime}$ profile in our 
model. Another similarity can be found in the bottom boundary of the resistive block at about $10 \mathrm{~km}$ depth below Sites 9 and 10. But the resistivity in the deeper part of the crust at Sites 6 to 8 is significantly different. The high resistive zone extends about $2 \mathrm{~km}$ below the surface in the TDEM result. Kanda et al. (1996) have also paid particular attention to the absence of the conductive layer below Sites 6 to 8, and tried to explain it by current channeling distortion. The extremely conductive layer near surface possibly reduces the resolution of the deeper structure. With regard to the B-B' profile, the layer whose resistivity is several tens of ohm meters is not detected in the MT investigation. This may indicate difference in resolution of the fine structure in the shallower part between the two methods. Largest difference between MT and TDEM results is seen at the deepest part. The lower crustal conductor was only revealed by MT, which possibly suggests the difference in sounding depth.

\section{Conclusion}

The correspondence between the hypocentral zone and its surrounding resistivity distribution was studied by analyzing the ELF- and the ULF-MT data taken in the seismically active area of the northern part of Miyagi Prefecture. By means of 2-D inversion with a 3-D/2-D treatment, the following two points were concluded.

(1) There is a lateral variation in resistivity at $4-10 \mathrm{~km}$ depths. The microearthquakes occur in the relatively conductive zone, and seismicity significantly decreases in the resistive block. The relatively conductive zone is likely due to fluids.

(2) By comparing the MT result with the TDEM result, both results indicate the near surface conductor at depths from 1 to $3.5 \mathrm{~km}$ and the bottom boundary of the resistive block at nearly the same depth. However TDEM has resolved the fine structures in the shallower part, while MT has revealed the deeper parts.

Acknowledgments. We greatly thank the Research Group for Crustal Resistivity Structure Japan for their allowance for the use of the MT data. Special acknowledgment goes to Dr. T. Uchida and Dr. Y. Ogawa, Geological Survey of Japan, for providing their MT-inversion programs. We also wish to thank Dr. A. Chave for providing the robust estimation program for magnetotelluric responses through the MTNET home page (http://www.cg.NRCan.gc.ca/ mtnetprogs/rrrmt.html). We would also like to acknowledge Mr. T. Kono, the Sanriku Observatory for Earthquakes and Volcanoes, Tohoku University, for supporting data and information of microseismicity in the northern Miyagi Prefecture. Subsequent version have been greatly improved by Dr. T. Harinarayana and by another anonymous referee. Some of the figures were created using GMT systems ver. 3.0 (Wessel and Smith, 1995). This study was partly supported by the Ministry of Education, Culture and Science, through Grantin-Aid for Co-operative Research (A), No. 05302022.

\section{References}

Bahr, K., Interpretation of the magnetotelluric impedance tensor: regional induction and local telluric distortion, J. Geophys., 62, 119-127, 1988.

Bahr, K., Electrical anisotropy and conductivity distribution functions of fractal random networks and of the crust: the scale effect of connectivity, Geophys. J. Int., 130, 649-660, 1997.

Chave, A. D. and J. T. Smith, On electric and magnetic field galvanic distortion tensor decompositions, J. Geophys. Res., 99, 4669-4682, 1994.

Chave, A. D., D. J. Thomson, and M. E. Ander, On the robust estimation of power spectra, coherences, and transfer functions, J. Geophys. Res., 92 , 633-648, 1987.
Frape, S. K. and P. Fritz, Water-rock interaction and chemistry of groundwaters from the Canadian Shield, Geochim. Cosmochim. Acta, 48, 16171627,1984

Gamble, T. D., W. M. Goubau, and J. Clarke, Magnetotellurics with a remote magnetic reference, Geophys., 44, 53-68, 1979.

Goto, T., Study on the electrical resistivity structure around the seismogenic zone in the Crust, Ph.D. Thesis, Kyoto Univ., 188 pp., 1997.

Goto, T., N. Oshiman, and N. Sumitomo, The resistivity structure around the hypocentral area of the Ebino Earthquake Swarm in Kyushu district, Japan, J. Geomag. Geoelectr., 49, 1279-1291, 1997.

Groom, R. W. and R. C. Bailey, Decomposition of magnetotelluric impedance tensors in the presence of local three-dimensional galvanic distortion, J. Geophys. Res., 94, 1913-1925, 1989.

Gupta, H. K., S. V. S. Sarma, T. Harinarayana, and G. Virupakshi, Fluids below the hypocentral region of Latur earthquake, India: Geophysical indicators, Geophys. Res. Lett., 23, 1569-1572, 1996.

Harinarayana, T., Combination of EM and DC measurements for upper crustal studies-A brief review, Proc. of 14th Workshop on Electromagnetic. Induction in the Earth, 193-214, 1998.

Hyndman, R. D., Dipping seismic reflectors, electrically conductive zones and trapped water in the crust over a subducting plate, J. Geophys. Res., 93, 13391-13405, 1988.

Jones, A. G., Static shift of magnetotelluric data and its removal in a sedimentary basin environment, Geophys., 53, 967-978, 1988.

Jones, A. G. and R. W. Groom, Strike-angle determination from the magnetotelluric impedance tensor in the presence of noise and local distortion: rotate at your peril!, Geophys. J. Int., 113, 524-534, 1993.

Jödicke, H., Water and graphite in the earth's crust—an approach to interpretation of conductivity models, Surv. Geophys., 13, 381-407, 1992.

Kanda, W., H. Utada, M. Mishina, and N. Sumitomo, A deep transient EM experiment in the northern part of Miyagi Prefecture, northeastern Japan, J. Geomag. Geoelectr., 48, 1265-1280, 1996.

Kariya, K. A. and T. J. Shankland, Electrical conductivity of dry lower crustal rocks, Geophys., 48, 52-61, 1983.

Kono, T., K. Nida, S. Matsumoto, S. Horiuchi, T. Okada, K. Kaihara, A. Hasegawa, S. Hori, N. Umino, and M. Suzuki, Microearthquake activity in the focal area of the 1962 northern Miyagi Prefecture (M 6.5), Zisin, 46, 85-93, 1993 (in Japanese with English abstract).

Mogi, T., K. Hongo, and K. Sassa, Electrical properties of fine grained soil, Butsuri Tansa (Geophys. Explor.), 39, 95-105, 1986 (in Japanese with English abstract).

Möller, P., S. M. Weise, E. Althaus, W. Bach, H. J. Behr, R. Borchardt, K. Bräuer, J. Drescher, J. Erzinger, E. Faber, B. T. Hansen, E. E. Horn, E. Huenges, H. Kämpf, W. Kessels, T. Kirsten, D. Landwehr, M. Lodemann, L. Machon, A. Pekdeger, H.-U. Pielow, C. Reutel, K. Simon, J. Walther, F. H. Weinlich, and M. Zimmer, Paleofluids and recent fluids in the upper continental crust: results from the German Continental Deep Drilling Program (KTB), J. Geophys. Res., 102, 18233-18254, 1997.

Nur, A., Dilatancy, pore fluids and premonitory variations of ts/tp travel times, Bull. Seismol. Soc. Am., 62, 1217-1222, 1972.

Ogawa, Y., Deep crustal resistivity structure revealed by wideband magnetotellurics-Tohoku and Hokkaido region-, Ph.D. Thesis, Univ. of Tokyo, 320 pp., 1992.

Oide, K, H. Nakagawa, and S. Kanisawa(eds.), Regional Geology of Japan, Part 2 Tohoku, 338 pp., Kyoritsu Shuppan Co., Ltd., 1989 (in Japanese).

Olhoeft, G. R., Electrical properties of granite with implications for the lower crust, J. Geophys. Res., 86, 931-936, 1981.

Rodi, A technique for improving the accuracy of finite element solutions for magnetotelluric data, Geophys. J. R. Astr. Soc., 44, 483-506, 1976.

Shankland, T. J. and M. E. Ander, Electrical conductivity, temperatures, and fluids in the lower crust, J. Geophys. Res., 88, 9475-9484, 1983.

Scholz, C. H., L. R. Sykes, and Y. P. Aggarwal, Earthquake prediction: A physical basis, Science, 181, 803-810, 1973.

Smith, J. T., Estimating galvanic-distortion magnetic fields in magnetotellurics, Geophys. J. Int., 130, 65-72, 1997.

Takagi, A., A. Hasegawa, and N. Umino, Focal mechanism of shallow earthquakes occurring in Tohoku district, northeastern Japan ${ }^{\dagger}$, Program. Abstr. Seismol. Soc. Jpn., No. 1, p. 124, 1973 (in Japanese).

Uchida, T., Smooth 2-D inversion for magnetotelluric data based on statistical criterion ABIC, J. Geomag. Geoelectr., 45, 841-858, 1993.

Uchida, T. and Y. Ogawa, Development of FORTRAN code for two-dimensional magnetotelluric inversion with smoothness constraint, OpenFile Report, Geological Survey of Japan, No. 205, 115 pp., 1993.

Utsu, T., Magnitude of earthquakes and occurrence of their aftershocks, Zisin, 10, 6-23, 1957 (in Japanese). 
Wessel, P. and W. H. F. Smith, New version of the Generic Mapping Tools released, EOS Trans. $A G U, \mathbf{7 6}(33), 329,1995$.

Yamada, N., Y. Teraoka, and M. Hata(Chief eds.), Geological map of Japan, scale 1:1,000,000, Geological Atlas of Japan, Geological Survey of Japan, p. 11, 1982.

Zhao, D., H. Kanamori, H. Negishi, and D. Wiens, Tomography of the source area of the 1995 Kobe Earthquake; evidence for fluids at the hypocenter? Science, 274, 1891-1894, 1996. $\dagger$ The title is translated in English by the author M. I.

M. Ichiki (e-mail: ichiki@eri.u-tokyo.ac.jp), M. Mishina (e-mail: mishina@aob.geophys.tohoku.ac.jp), T. Goto (e-mail: tgoto@auecc.aichiedu.ac.jp), N. Oshiman (e-mail: g53032@sakura.kudpc.kyoto-u.ac.jp), N. Sumitomo (e-mail: sumitomo@rcep.dpri.kyoto-u.ac.jp), and H. Utada (email: utada@utada-sun.eri.u-tokyo.ac.jp) 